\title{
State-of-the-Art Methods for Electric Power Systems Voltage Stability Analysis
}

\author{
T.M. Al-Khusaibi ${ }^{*}$, K. A. Ellithy ${ }^{* \star}$ and M.R. Irving ${ }^{* \star}$
}

*Ministry of Electricity and Water, P.O. Box 105 Ruwi, Postal Code 112, Ruwi, Sultanate of Oman ${ }^{* *}$ Department of Electrical \& Electronics Engineering, Sultan Qaboos University,P.O. Box 33, Postal Code 123, Muscat, Sultanate of Oman *** Department of Electrical Engineering and Electronics, Brunel University, UK

اللرق الحيثة الحللل السقرال الجهد الكهرب للام الفوى الكهربية

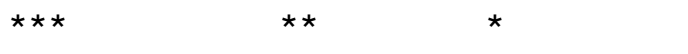

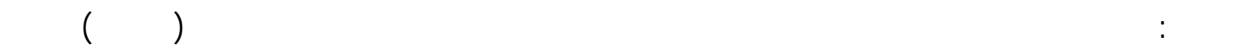

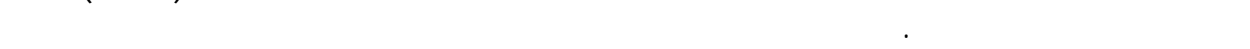

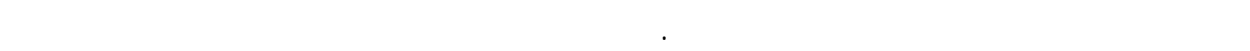

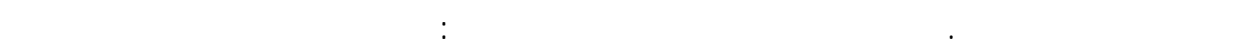

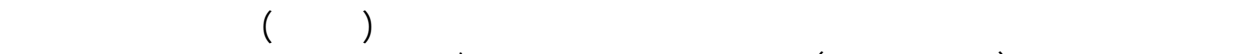

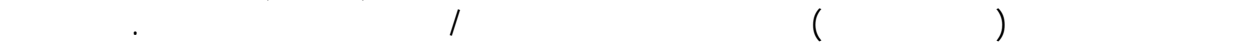

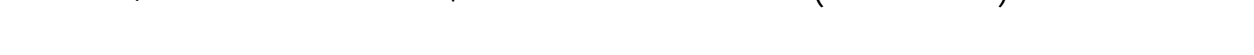

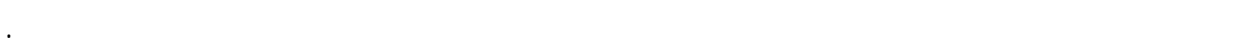

مق ظبيق بعض الطرق الموصوفة بالورقة على نموذج ظطلم القوى المعروف ب (IEEE 30-bus system).

\begin{abstract}
This paper presents a literature survey on the subject of voltage stability analysis of power systems. The survey describes several published methods and techniques used to determine voltage stability indices. These indices predict proximity to voltage instability and collapse problems. The $\mathrm{Q}-\mathrm{V}$ and $\mathrm{P}-\mathrm{V}$ curves; singular value decomposition; modal analysis; test function; reduced determinant; loading margin by multiple power flow solutions; local load margins; thevenin/load impedance; and energy function are the methods which have been decribed in the paper. The methods described are based on the original work that first proposed them. They are based on the powerflow system model, where the variation of real and reactive powers are assumed to be the main parameters driving the system to voltage instability. Some of the described methods were applied on the IEEE 30-bus power system.
\end{abstract}




\section{AL-KHUSAIBI, ELLITHY and IRVING}

\section{CONTENTS}

1. Introduction

2. Methods of Voltage Stability Analysis $\quad 249$

2.1 Q-V and P-V Curves Method (Continuation Method) 249

2.2 Singular Value Decomposition Method $\quad 250$

2.3 Modal Analysis Method $\quad 252$

2.4 The Test Function Method 253

2.5 The Reduced Determinant Method 254

2.6 The Loading Margin Method by Multiple Power-Flow Solutions 255

2.7 The Local Load Margins Method 255

2.8 The Thevenin /Load Impedance $\left(\mathrm{Z}_{\mathrm{ii}} / \mathrm{Z}_{\mathrm{i}}\right)$ Method 256

2.9 The Energy Function Method 256

3. Numerical Results 257

4. Conclusions $r 262$

5. References 262

\section{Introduction}

Droblems related to voltage instability in power systems have been experienced by many utilities and are today, in many countries, one of the main concerns in power system operation and planning. Forcing the transmission lines (network) to operate close to their thermal capability (maximum capacity) to avoid the cost required for new lines and power plant facilities has lead to many of these voltage instability problems, due to inadequate reactive power margin. Several networks collapse caused by voltage instability problems were reported in various countries such as USA, France and Japan (Taylor, 1994; Baribier and Barret, 1980; Kurita and Sakurai, 1986).

The phenomenon of voltage instability in power systems is characterized by a continuous decrease (drop) of system voltage, which is gradual at the initial stage and then becomes rapid. Generally this is triggered by a disturbance or change in operating conditions, which creates increased demand for reactive power in excess of system capacity. The disturbance or change in operating conditions which can lead to voltage instability and collapse could be related to the unexpected increase of load level or to a sudden loss of transmission line, transformer, a generator, a slow clearing of a system fault or response of various control systems (Miller, 1982).

Kundur (1994) has characterized the voltage collapse based on actual incidents where he described this phenomenon, indicating the initiating causes, the problem itself and the resultant phenomenon including the time frame of collapse. In the course of finding solutions to voltage stability problems, it is very helpful to classify them into two categories: large-disturbance voltage stability and small disturbance voltage stability (Gao et al, 1992; Kundur, 1994). To study and analyze large-disturbance voltage stability, a dynamic performance analysis is required using non-linear time simulations. This is a time consuming process in terms of CPU time and the engineering effort required for analysing the results. Smalldisturbance voltage stability on the other hand can be studied with steady state or static approaches using linearization of the dynamic equations at a given operating point.

Most of the time, voltage stability analysis requires study of the wide range of system conditions and various contingencies. For this type of applications, the steady state or static analysis approach is more suitable and if properly used can provide insight into the voltage instability problem (Gao et al, 1992).

The analysis of voltage stability for a given system state involves the examination of the following two-aspects (Kundur, 1994):

- Proximity of voltage instability: How close is the system to voltage instability?

- Mechanism: What are the voltage weak points and what areas are involved? How and why does instability occur? What are the contributing factors? Proximity provides information regarding voltage 


\section{STATE OF THE ART METHODS FOR ELECTRIC POWER SYSTEMS}

security whereas the mechanism provides useful information, which may lead to prevention of voltage instability (such as system modification or operating policies and strategies), thus avoiding voltage collapse.

A number of techniques and methods have been proposed in the literature for voltage stability analysis using steady state (static) method (Mansour et al, 1994; Kundur 1994; Gao et al, 1992; Venkov, 1975; IEEE Working Group, 1990; Cigre Task Force, 1993) . In the past, some utilities have used P-V and Q-V curves at specific small number of load buses (D’Aquila et al, 1993; Pal 1993; Suzuki et al, 1992; Mansour et al, 1994; Vaahedi, 1999; Schluter, 1998). Most of these approaches are based on power flow modes which are time consuming and do not provide insight into the causes of stability problems (Kundur, 1994). Other techniques have been suggested such as modal analysis (Gao et al, 1992; Morrison et al, 1993; Kundur, 1994; Mansour et al, 1994; Ellithy et al 2000), singular value decomposition (Löf et al, 1992; Löf et al, 1993; Liu et al, 1998), sensitivity analysis (Bakovic and Phadek, 1992; Flatabo and Dommel 1990), energy function (Overbye and DeMacro, 1995; El-Keib and Ma, 1995), test functions (Seydel, 1988), reduced Jacobian determinant (Ganizares et al, 1995), reactive power optimization (Tamura et al, 1983), Thevenin and load impedance $\left(\mathrm{Z}_{\mathrm{ii}} / \mathrm{Z}_{\mathrm{i}}\right)$ indicator (Chebbo et al, 1992), artificial neural network (Jeyasurya, 1990; El-Keib and Ma, 1995), neuro-fuzzy networks (Liu et al, 1998), local margins (Nagao et al, 1997), and loading margin by multiple power-flow solutions (Yorino et al, 1997). These methods have wider approach and can predict voltage collapse in complex networks.

\section{Methods of Voltage Stability Analysis}

Methods to predict proximity to voltage collapse are considered an important issue by power researchers and technical staff in power systems operation, as these methods could be used on-line or offline to help dispatchers to know how close the system is to collapse. The main objective of these methods is to determine scalar magnitude that can be monitored as system parameters change. The methods should have predictable results and should be computationally inexpensive, especially for online system observation. This section describes some of the methods mentioned in the literature, with special consideration given to the modal analysis and the singular value decomposition (SVD) method, due to their capability of providing information regarding voltage stability of the complete system. Furthermore, they can also identify the individual voltage unstable mode and the degrees of participation of various components in the power system as well as provide better information with respect to the mechanism of voltage instability.

\subsection{Q-V and P-V Curves Method (Continuation Method)}

Q-V and P-V curves are currently in use at some utilities (Suzuki et al, 1992) for determining proximity to voltage collapse so that operators can make timely preventive measures to avoid system loss. The Q-V curves (reactive power-voltage curves) are used in this voltage stability study since they directly assess shortage of reactive power.

The Q-V curve technique is a general method of assessing voltage stability. These curves are presently the workhorse method of voltage stability assessment at many utilities. Q-V curves show the sensitivity and variation of bus voltages with respect to the reactive power injection. A typical Q-V curve is shown in Figure 1. The Q axis shows the reactive power that needs to be added or removed from bus to maintain a given voltage at a given load. From Figure 1-b, it can be seen that the curve gives the reactive power margin at the test bus. The reactive power margin is the mega volt-amps reactive (MVAR) distance from the operating point to the furthest right hand point of the curve. This curve can be used as an index for voltage instability ( $\mathrm{dQ} / \mathrm{dV}$ becomes negative). Near the nose of Q-V curve, sensitivities get very large and then reverse their sign. The Jacobian matrix becomes singular at the nose of the curve. This is called a saddle bifurcation node (Yokoyama and Sekine, 1989).

The P-V curves (active power-voltage curves) are the most widely used method of estimating voltage 
security, providing megawatt (MW) margin type indices. The P-V curve is used to determine the MW distance from the operating point to the critical voltage. A typical P-V curve is shown in Figure 1-a. The P$\mathrm{V}$ curves are also useful for conceptual analysis when the load characteristics as a function of voltage are analyzed. While P-V curves are helpful in understanding the phenomena of voltage stability and collapse, they are not so useful for determining the reactive power support needed at various points in a power system.

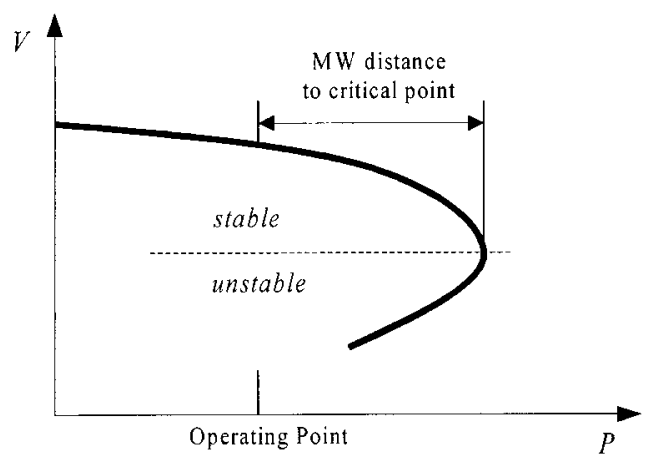

(a) P-V Curve

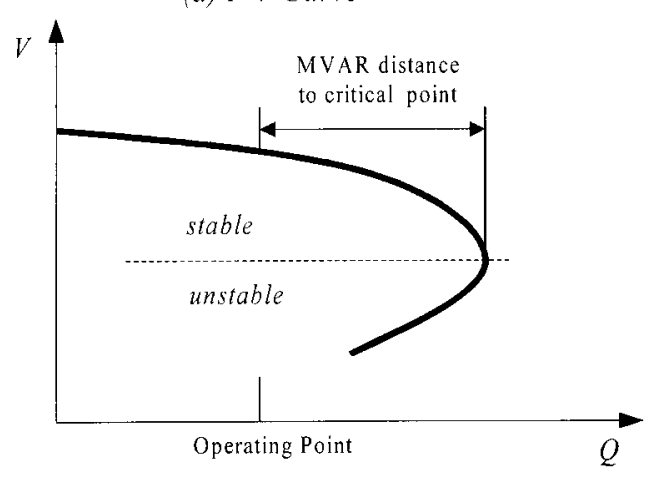

(b) Q-V Curve

Figure 1. P-V and Q-V curves

\subsection{Singular Value Decomposition Method}

The Singular Value Decomposition (SVD) method is a very useful tool for analyzing matrices and related problems in many fields. It has been applied to power systems for voltage stability analysis to obtain decomposition of the Jacobian matrix (Löf et al, 1993). For a real square matrix A of size n, the singular value decomposition is given by

$$
\mathrm{A}=U \mathrm{~S} V^{T}=\sum_{i=1}^{n} \sigma_{i} u_{i} v_{i}^{T}
$$

Where $U$ and $V$ are $\mathrm{n} \times \mathrm{n}$ orthogonal matrices, $u_{i}$ and $v_{i}$ are called the left and right singular vectors respectively, and $\mathrm{S}$ is a diagonal matrix with

$$
\mathrm{S}(A)=\operatorname{diag}\left[\sigma_{i}(A)\right] \quad \mathrm{i}=1,2,3, \ldots, \mathrm{n}
$$




\section{STATE OF THE ART METHODS FOR ELECTRIC POWER SYSTEMS}

where $\sigma_{i} \geq 0$ for all $\mathrm{i}$. The diagonal elements in the matrix $\mathrm{S}$ are usually ordered so that $\sigma_{1} \geq \sigma_{2}$ $\geq \sigma_{3} \geq \ldots . . \sigma_{\mathrm{n}} \geq 0$. If the matrix A has rank $\mathrm{r}(\mathrm{r} \leq \mathrm{n})$, its singular values $\sigma_{1}, \sigma_{2}, \sigma_{3}, \ldots \sigma_{\mathrm{r}}$ are the only nonzero entries in the nxn diagonal matrix $\mathrm{S}$.

To use the above theory for voltage stability analysis, the linear power-flow equation based on the Newton-Raphson method has to be found which is established by the power-flow Jacobian matrix $\mathbf{J}$

$$
\left[\begin{array}{c}
\Delta P \\
\Delta Q
\end{array}\right]=\left[\begin{array}{ll}
J_{P \theta} & J_{P V} \\
J_{Q \theta} & J_{Q V}
\end{array}\right]\left[\begin{array}{l}
\Delta \theta \\
\Delta V
\end{array}\right]
$$

where $\Delta P$ is the incremental change in bus real power, $\Delta Q$ is the incremental change in bus reactive power, $\Delta \theta$ is the incremental change in bus voltage angle and $\Delta V$ is the incremental change in bus voltage magnitude. Hence the full Jacobian matrix can be written as,

$$
J=\left[\begin{array}{ll}
J_{P \theta} & J_{P V} \\
J_{Q \theta} & J_{Q \theta}
\end{array}\right]
$$

The equation is re-written as,

$$
\left[\begin{array}{l}
\Delta P \\
\Delta Q
\end{array}\right]=J\left[\begin{array}{l}
\Delta \theta \\
\Delta V
\end{array}\right]
$$

Now, if the singular value decomposition is applied to J, one has

$$
J=U \mathrm{~S} V^{T}=\sum_{i=1}^{n} \sigma_{i} u_{i} v_{i}^{T}
$$

The minimum singular value, $\sigma_{n}(\mathrm{~J})$ is a measure of how close the Jacobian to singularity. In the case of a small distrubance, let

$$
\left[\begin{array}{l}
\Delta P \\
\Delta Q
\end{array}\right]=u_{n}
$$

where $u_{n}$ is the last column of $\mathrm{U}$, and

$$
\left[\begin{array}{l}
\Delta \theta \\
\Delta V
\end{array}\right]=\sigma_{n}^{-1} v_{n}
$$

where $v_{n}$ is the last column of $V$.

From the above equations it can be concluded that for the minimum singular value and corresponding left and right singular vectors (Lof et al, 1992), the following apply:

- The smallest singular value $\sigma_{n}$ is an indicator of the proximity to the steady state stability limit.

- The right singular vector, $v_{n}$ corresponding to $\sigma_{n}$ indicates sensitive voltage. 


\section{AL-KHUSAIBI, ELLITHY and IRVING}

- The left singular vector, $u_{n}$ corresponding to $\sigma_{n}$ indicates the most sensitive direction for changes of active and reactive power injections.

\subsection{Modal Analysis Method}

As mentioned in Conference Internationale Des Grands Reseaux Electriques a Haute Tension ( CIGRE ) Task Force, (1993), there is a need to have an analytical method which can predict voltage collapse in complex power system networks. There is also a need to consider more detailed steady state models for main system components such as generators, Static Var Compensators (SVCs), induction motors and voltage dependent static loads. The modal analysis (eigenvalue analysis) method was proposed by Gao et al, (1992), to meet the above requirements. It involves the calculation of a small number of eigenvalues and related eigenvectors of a reduced Jacobian matrix. However, by using the reduced Jacobian, the focus is on voltage and reactive power characteristics.

From equation (B-3), and at any operating point we may keep P constant and voltage stability is evaluated by considering incremental changes between $\mathrm{Q}$ and $\mathrm{V}$. Based on the above assumption let $\Delta P=0$ in equation (B-3), so that

$$
\Delta Q=\left\lfloor J_{Q V}-J_{Q \theta} J_{P \theta}^{-1} J_{P V}\right\rfloor \Delta V=J_{R} \Delta V
$$

and

$$
\Delta V=J_{R}^{-1} \Delta Q
$$

where

$$
J_{R}=\left[J_{Q V}-J_{Q \theta} J_{P \theta}^{-1} J_{P V}\right]
$$

$J_{R}$ is called the reduced Jacobian matrix of the system and it directly relates the bus voltage magnitude to the bus reactive power injection. The elimination of the real power and angle part from equation (B-1) allows us to concentrate on the analysis of the reactive demand and supply problem of the system and also minimize the computational effort (Gao et al, 1992).

The eigenvalues and eigenvectors of the reduced Jacobian matrix lead to the identification of voltage stability characteristics of the system. The eigenvalues identify the different modes, which may create the voltage instability of the system. The proximity to instability is provided relatively by the magnitude of the eigenvalues and the mechanism of instability is provided by the eigenvectors.

Let:

$$
J_{R}=\zeta \Lambda \eta
$$

where $\zeta$ is the right eigenvector matrix of $J_{R}, \Lambda$ is the diagonal eigenvalue matrix of $J_{R}$, and $\eta$ is the left eigenvector matrix of $J_{R}$.

From equations (C-2) and (C-4), we have

$$
\Delta V=\zeta \Lambda^{-1} \eta \Delta Q=\sum_{i} \frac{\zeta_{i} \eta_{i}}{\lambda_{i}} \Delta Q
$$

Each eigenvalue and the corresponding right and left eigenvectors, define the $i$ th mode of the system. The $i$ th modal reactive power variation is:

$$
\Delta Q_{m i}=k_{i} \zeta_{i}
$$




\section{STATE OF THE ART METHODS FOR ELECTRIC POWER SYSTEMS}

The corresponding $i$ th modal voltage variation is:

$$
\Delta V_{m i}=\frac{1}{\lambda_{i}} \Delta Q_{m i}
$$

It is seen that when the reactive power variation is along the direction of $\zeta_{i}$, the corresponding voltage variation is also along the same direction and the magnitude is amplified by a factor which is equal to the magnitude of the inverse of the corresponding eigenvalues.

The system is voltage stable if all the eigenvalues of $J_{R}$ are positive, and is voltage unstable if at least one of the eigenvalues is negative. The smaller the magnitudes of the eigenvalues, the closer the corresponding modal voltage to being voltage unstable. If the eigevalue is zero, the system is on the verge of voltage instability.

The elements (bus, branch and generator) which participate in each mode can be obtained as follows: Bus Participation Factors: The participation factor of bus k to mode i (Kundur, 1994) is given by

$$
P_{k i}=\zeta_{k i} \eta_{i k}
$$

$P_{k i}$ indicates the contribution of the $i$ th eigenvalue at bus $k$. The size of bus participation in a given mode indicates the effectiveness of remedial actions applied at that bus in stabilizing the mode. The bigger the value of $P_{k i}$ the closer the load bus (load area) to voltage instability.

Branch and Generator Participation Factors: The participation factor of branch $l j$ to mode $i$ (Kundur, 1994) is given by

$$
P_{l j i}=\frac{\Delta Q_{\text {loss }} \text { for branch } j}{\max \Delta Q_{\text {loss }} \text { for all branches }}
$$

The branches with high $P_{l j i}$ are those which cause mode $i$ to be weak.

The participation factor of generator $g k$ to mode $i$ is

$$
P_{g k}=\frac{\Delta Q_{m} \text { for generator } m}{\max \Delta Q \text { for all generators }}
$$

Generators with high $P_{g k i}$ are those which maintain stability of mode $i$.

\subsection{The Test Function Method}

This voltage stability index is based on a family of scalar test functions, $t_{l k}$ (Seydel, 1988) given as,

$$
t_{l k}=\left|e_{l}^{T} J J_{l k}^{-1} e_{l}\right|
$$

Where $\mathrm{J}$ corresponds to the system jacobian matrix, $e_{l}$ is a unit vector, and

$$
J_{l k}=\left(I-e_{l} e_{l}^{T}\right) J+e_{l} e_{k}^{T}
$$


where I represents the identity matrix. At the voltage collapse point $J$ is singular and $J_{l k}$ is guaranteed not to be singular, and if $l=k=c$, then

$$
t_{c c}=\left|e_{c}^{T} J J_{c c}^{-1} e_{c}\right|
$$

The test function family is a function of the system variables and parameters. As the system approaches collapse, the system variable change, and the critical test function $t_{c c}$ shows a quadratic shape as a function of load margin $\Delta \beta$. Thus,

$$
\Delta \beta \approx a t_{c c}^{2}
$$

where $a$ is a scalar constant. This allows $t_{\mathrm{cc}}$ to be used to determine the system proximity to collapse. The test function index is independent of system size, which is not the case for sensitivity factors. However, determining the critical buses $c$ is a disadvantage of using (D-3) for $t_{c c}$ as this might lead to significant computational costs.

\subsection{The Reduced Determinant Method}

This method or technique as defined by Ganizares et al, (1995), is based on assuming that active and reactive power variations occur only at the system bus of interest $l$. The load-follow Jacobian matrix can be re-ordered so that the mismatch powers for bus $l$ are the last ones. This gives:

$$
\left[\begin{array}{c}
0 \\
0 \\
\Delta P_{l} \\
\Delta Q
\end{array}\right]=\left[\begin{array}{ll}
A & B \\
C & D
\end{array}\right]\left[\begin{array}{c}
\Delta \theta \\
\Delta E \\
\Delta \theta_{l} \\
\Delta E_{l}
\end{array}\right]
$$

where A, B, C and D represent the corresponding blocks of Jacobian matrix $J$. Also D is a 2 x 2 matrix. Equation (E-1) can be reduced to:

$$
\left[\begin{array}{c}
\Delta P_{l} \\
\Delta Q_{l}
\end{array}\right]=D_{l l}^{\prime}\left[\begin{array}{l}
\Delta \theta_{i} \\
\Delta V_{l}
\end{array}\right]
$$

where

$$
D_{l l}^{\prime}=D-C A^{-1} B
$$

The matrix $D_{l l}^{\prime}$ is well defined at operating points. Thus, the determinant of $D_{l l}^{\prime}$ is

$$
\operatorname{det} D_{l l}^{\prime}=\frac{\operatorname{det} J}{\operatorname{det} A}
$$

$D_{l l}^{\prime}$ becomes zero only at the collapse point. 


\section{STATE OF THE ART METHODS FOR ELECTRIC POWER SYSTEMS}

Results for changes in the loading factor $\beta$ obtained for different operating points show that det $D_{l l}^{\prime}$ provides similar information and behavior as that of a test function. Hence the loading margin can also be defined using $\operatorname{det} D_{c c}^{\prime}$ instead of $t_{c c}$ in equation (D-3). Matrix $D_{l l}^{\prime}$ in (E-3) can be obtained by a partial factorization of the corresponding load-flow Jacobian $J$. This suggests slightly less computation cost than determining the test function $t_{l k}$ in (D-1).

\subsection{The Loading Margin Method by Multiple Power-Flow Solutions}

This method calculates an approximation to the closest loadability by using a pair of multiple power flow solutions (Yorino et al, 1997). The loading margin index is defined as the amount of additional load increase (specific pattern) for a particular operating point that may cause a voltage collapse. Loading margin is widely accepted as an index of voltage collapse and can be easily generalized to be associated with the margin of some other parameter that is varied until the system reaches voltage collapse. For example: if the loads were temperature dependent, then one could define a "temperature margin" to voltage collapse. The advantages of the loading margin can be summarized as:

- It is straightforward and can be easily understood.

- It is not based on a specific model.

- It is an accurate index.

- It accounts for the pattern of load increase.

The disadvantages of the loading margin can be summarized as:

- It is computationally more expensive.

- It requires the assumption of a direction load increase.

\subsection{The Local Load Margins Method}

This index of proximity (Nagao et al, 1997) is based on the distance from the initial load ( $P_{o i}$ in MW) to the nose of the $\mathrm{P}-\mathrm{V}$ curve $\left(P_{\max i}\right.$ in $\left.\mathrm{MW}\right)$. At a fixed power factor and as the load at node $i$ is increased, the load margin $P_{l m g i}$ assumes that at other loads the loads remain constant. Hence,

$$
P_{l m g i}=\frac{P_{\max i}-P_{o i}}{P_{\max i}}
$$

This equation allows the computation of a voltage stability margin for each load point. Its computation is relatively easy. However, a voltage stability margin has to be evaluated for the whole power system. Therefore, one needs to calculate $P_{\max }$ for the number of load nodes in the system, which may be impractical.

By introducing a factor $h$ the problem of computing $P_{\max }$ can be considered as a problem of calculating $h$. Thus, $P_{\text {lmgi }}$ index defined in (G-1) can be expressed in terms of $h$ as follow:

$$
P_{l m g i}=\frac{h P_{o i}-P_{o i}}{h P_{o i}}=\frac{h-1}{h}
$$




\section{AL-KHUSAIBI, ELLITHY and IRVING}

This index is strongly based on a power flow model and therefore, more studies are required for other types of load models. Computational cost is the main disadvantage of this index, as these local margins have to be calculated for all the load buses so that proximity to collapse can be predicted with more accuracy.

\subsection{The Thevenin/Load Impedance $\left(Z_{\mathrm{ii}} / Z_{\mathrm{i}}\right)$ Method}

It has been shown by Chebo et al, (1992), that the voltage collapse of the system at load bus $i$ occurs when the impedance of the load is equal to the equivalent impedance looking into the port between $i$ and the ground i.e. $Z_{\mathrm{ii}}=\mathrm{Z}_{\mathrm{ii}}\left(\mathrm{Z}_{\mathrm{ii}} / \mathrm{Z}_{\mathrm{i}}=1\right)$. Where $\mathrm{Z}_{\mathrm{ii}}$ is the magnitude of Thevenin impedance seen by load $i$ and $\mathrm{Z}_{\mathrm{i}}$ is the magnitude of impedance of load $i$. For a secure system at bus $i$ we must have $Z_{\mathrm{ii}} / Z_{\mathrm{i}}$ less than one $\left(Z_{\mathrm{ii}} / Z_{\mathrm{i}}<1\right)$. This voltage collapse proximity indicator $\left(Z_{\mathrm{ii}} / Z_{\mathrm{i}}\right)$ has also been used by these authors for reactive power dispatch to minimize the possibility of voltage collapse in the system.

\subsection{The Energy Function Method}

The energy function method has been described by DeMacro and Overbye, (1990), where a scalar energy function is measured depending on the system voltage magnitudes and phase angle. This scalar measure has a property of defining a local minimum of this energy. The energy function defines the height between the operable solution and a low voltage solution. It is also called potential barrier (Jeyasurya, 1994). As the power system approaches operating point to voltage collapse, the height of the barrier decreases.

The height of the potential barrier can provide an indicator of the proximity to voltage collapse. The energy measure is computed as:

$$
\begin{aligned}
\text { Energy measure }= & -\frac{1}{2} \sum_{i=1}^{n} \sum_{j=1}^{n} B_{i j}\left|v_{i}^{u}\right|\left|V_{j}^{u}\right| \cos \left(\theta_{i}^{u}-\theta_{j}^{u}\right) \\
& +\frac{1}{2} \sum_{i=1}^{n} \sum_{j=1}^{n} B_{i j}\left|V_{i}^{s}\right|\left|V_{j}^{s}\right| \cos \left(\theta_{i}^{s}-\theta_{j}^{s}\right) \\
& +\sum_{i=1}^{n} \int_{V_{i}^{s}}^{V_{i}^{u}} \frac{Q_{i}(x)}{x} d x-P^{T}\left(\theta^{u}-\theta^{s}\right) \\
& -\sum_{i=1}^{n} \sum_{j=1}^{n} G_{i j}\left|V_{i}^{s} \| V_{j}^{s}\right| \cos \left(\theta_{i}^{s}-\theta_{j}^{s}\right)\left(\theta_{i}^{u}-\theta_{i}^{s}\right) \\
& +\sum_{i=1}^{n}\left(V_{i}^{s}\right)^{-1} \sum_{j=1}^{n} G_{i j}\left|V_{i}^{s} \| V_{i}^{s}\right| \sin \left(\theta_{i}^{s}-\theta_{j}^{s}\right)\left(V_{i}^{n}-V_{i}^{s}\right),
\end{aligned}
$$

where $n$ is the number of buses in the system, $G_{\mathrm{ij}}$ and $B_{\mathrm{ij}}$ are the elements of the bus admittance matrix; $V_{\mathrm{i}}$ is the bus voltage magnitude; $\theta$ the bus voltage angle, $\mathrm{P}$ the vector of net real power into each bus, and $Q_{\mathrm{i}}$ the reactive power into bus $i$. The superscript $s$ stands for an operable solution and $u$ for the type-one lowvoltage solution for the same loading condition.

This method provides an indicator or a measure, where the energy measure decreases as the load increases. It is approximately zero near the point of voltage collapse. A large value of the energy measure at 


\section{STATE OF THE ART METHODS FOR ELECTRIC POWER SYSTEMS}

lightly loaded conditions indicates that the system is away from voltage collapse. The sensitivities of the energy measure at different controllers can be determined.

\section{Numerical Results}

The singular value decomposition method, modal analysis method, and Q-V curves technique have been applied to the IEEE 30- bus system. Figure 2 shows the single- line diagram of the IEEE 30-bus system. This system is a part of the American Electric Power Service Corporation network, which is made available to electric utility industry as a standard test case for evaluating various analytical methods and computer programs for the solutions of power system problems. A MATLAB computer program (Ellithy et $a l, 2000)$ was used to obtain the power-flow solutions and the corresponding matrices.

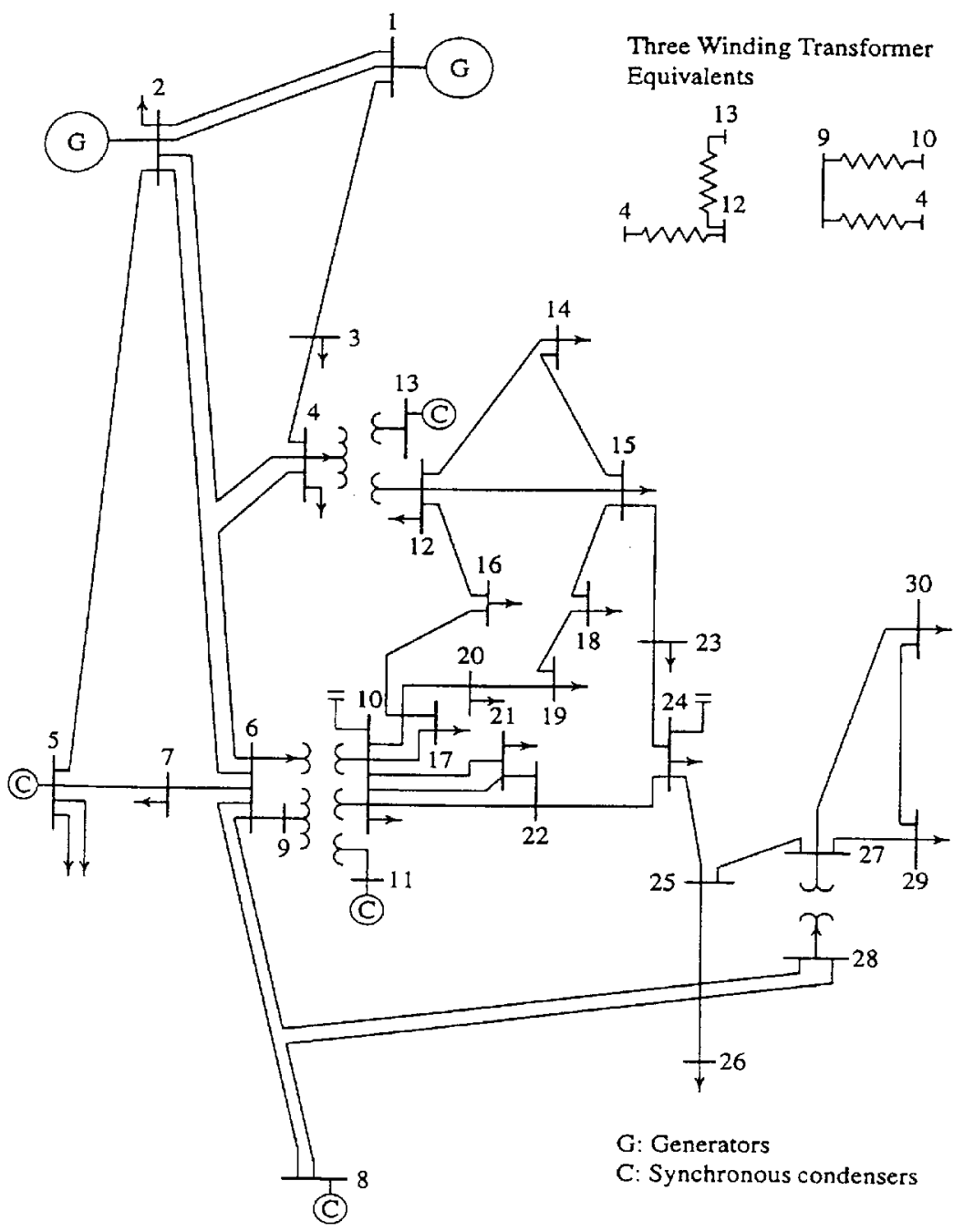

Figure 2. IEEE 30-Bus Power System 


\section{AL-KHUSAIBI, ELLITHY and IRVING}

Table 1. Power-flow result for base case

\begin{tabular}{|c|c|c|c|c|c|c|}
\hline \multirow[b]{2}{*}{$\begin{array}{c}B U S \\
\#\end{array}$} & & \multicolumn{3}{|c|}{ GENERATION } & \multicolumn{2}{|c|}{ Load } \\
\hline & $\begin{array}{c}\text { Voltage } \\
\text { Magnitude } \\
\text { (p.u) }\end{array}$ & $\begin{array}{c}\text { Voltage Angle } \\
\text { (p.u) }\end{array}$ & $\begin{array}{l}P_{g} \\
\text { (p.u) }\end{array}$ & $\begin{array}{c}Q_{g} \\
\text { (p.u) }\end{array}$ & $\begin{array}{c}P_{L} \\
\text { (p.u) } \\
\end{array}$ & $\begin{array}{c}\mathrm{Q}_{\mathrm{L}} \\
\text { (p.u) }\end{array}$ \\
\hline 1 & 1.060 & 0.000 & 2.614 & -0.130 & 0.000 & 0.000 \\
\hline 2 & 1.043 & -5.509 & 0.400 & 0.568 & 0.217 & 0.127 \\
\hline 3 & 1.019 & -7.987 & 0.000 & 0.000 & 0.024 & 0.012 \\
\hline 4 & 1.010 & -9.651 & 0.000 & 0.000 & 0.076 & 0.016 \\
\hline 5 & 1.010 & -14.414 & 0.000 & 0.394 & 0.942 & 0.190 \\
\hline 6 & 1.009 & -11.378 & 0.000 & 0.394 & 0.942 & 0.190 \\
\hline 7 & 1.001 & -13.144 & 0.000 & 0.000 & 0.228 & 0.109 \\
\hline 8 & 1.010 & -12.135 & 0.000 & 0.404 & 0.300 & 0.300 \\
\hline 9 & 1.048 & -14.522 & 0.000 & 0.000 & 0.000 & 0.000 \\
\hline 10 & 1.040 & -16.172 & 0.000 & 0.000 & 0.058 & 0.020 \\
\hline 11 & 1.082 & -14.522 & 0.000 & 0.177 & 0.000 & 0.000 \\
\hline 12 & 1.054 & -15.438 & 0.000 & 0.127 & 0.000 & 0.000 \\
\hline 13 & 1.071 & -15.438 & 0.000 & 0.127 & 0.000 & 0.000 \\
\hline 14 & 1.038 & -16.337 & 0.000 & 0.000 & 0.062 & 0.016 \\
\hline 15 & 1.033 & -16.406 & 0.000 & 0.000 & 0.082 & 0.025 \\
\hline 16 & 1.041 & -16.022 & 0.000 & 0.000 & 0.035 & 0.018 \\
\hline 17 & 1.035 & -16.336 & 0.000 & 0.000 & 0.090 & 0.058 \\
\hline 18 & 1.023 & -17.025 & 0.000 & 0.000 & 0.032 & 0.009 \\
\hline 19 & 1.020 & -17.200 & 0.000 & 0.000 & 0.095 & 0.034 \\
\hline 20 & 1.024 & -17.001 & 0.000 & 0.000 & 0.022 & 0.007 \\
\hline 21 & 1.025 & -16.616 & 0.000 & 0.000 & 0.175 & 0.112 \\
\hline 22 & 1.025 & -16.600 & 0.000 & 0.000 & 0.000 & 0.000 \\
\hline 23 & 1.018 & -16.767 & 0.000 & 0.000 & 0.032 & 0.016 \\
\hline 24 & 1.006 & -16.901 & 0.000 & 0.000 & 0.087 & 0.067 \\
\hline 25 & 0.983 & -16.279 & 0.000 & 0.000 & 0.000 & -0.000 \\
\hline 26 & 0.964 & -16.729 & 0.000 & 0.000 & 0.035 & 0.023 \\
\hline 27 & 0.977 & -15.626 & 0.000 & 0.000 & 0.000 & 0.000 \\
\hline 28 & 1.008 & -11.984 & 0.000 & 0.000 & 0.000 & 0.000 \\
\hline 29 & 0.956 & -16.978 & 0.000 & 0.000 & 0.024 & 0.009 \\
\hline 30 & 0.944 & -17.951 & 0.000 & 0.000 & 0.106 & 0.019 \\
\hline
\end{tabular}

Modal analysis was applied for two cases (base case and the stressed case). The stressed case was obtained by increasing the reactive power at bus number 30. Table 1 shows the power-flow results for the base case. The eigenvalues of the two cases are shown in Table 2. From Table 2, it can be seen that all eigenvalues are positive indicating that the system is voltage stable. The eigenvalue $\lambda_{1}$ is the least stable mode (critical mode). For the stressed case, the system is on the verge of instability $\left(\lambda_{1}=0.0366\right)$ but not actually unstable.

Table 3 gives the participation factors of the critical mode $\lambda_{1}$ for the base and stressed cases. From the participation factors of the base case, it is clearly seen that the highest participation factor corresponds to the load bus 30 . Based on this information, bus 30 is the weakest bus in the system. It can be concluded that the 


\section{STATE OF THE ART METHODS FOR ELECTRIC POWER SYSTEMS}

power stress in bus 30 can lead to voltage instability. Bus 30 was stressed and the results have confirmed that it is the weakest bus and the critical eigenvalue mode became much smaller.

Table 2. Eignvalues and singular value decomposition of Jacobian matrix $J_{R}$

\begin{tabular}{|c|c|c|c|c|}
\hline \multirow[b]{2}{*}{ Eigenvalue } & \multicolumn{2}{|c|}{ Modal Analysis } & \multicolumn{2}{|c|}{ Singular Value Decomposition } \\
\hline & & & & \\
\hline$\lambda_{i}$ & Base Case & Stressed Case & Base Case & Stressed Case \\
\hline 1 & $0.5) 60$ & $0.03 \div 1$ & $0 .: 060$ & 10366 \\
\hline 2 & 1.0238 & 0.8235 & 1.0238 & 0.8265 \\
\hline 3 & 1.7267 & 1.3301 & 1.7267 & 1.3338 \\
\hline 4 & 3.5808 & 3.3288 & 3.5808 & 3.3411 \\
\hline 5 & 4.0507 & 3.5145 & 4.0507 & 3.5224 \\
\hline 6 & 5.4527 & 3.9509 & 5.4525 & 3.9508 \\
\hline 7 & 6.0207 & 5.1156 & 6.0207 & 5.1171 \\
\hline 8 & 7.4360 & 6.3687 & 7.4361 & 6.3751 \\
\hline 9 & 8.7857 & 8.5863 & 8.7857 & 8.5864 \\
\hline 10 & 11.0447 & 10.7369 & 11.0442 & 10.7383 \\
\hline 11 & 13.6334 & 12.3384 & 13.6333 & 12.3410 \\
\hline 12 & 13.7279 & 13.3416 & 13.7278 & 13.3416 \\
\hline 13 & 16.3753 & 14.7664 & 16.3757 & 14.7719 \\
\hline 14 & 18.0785 & 17.5596 & 18.0784 & 17.5601 \\
\hline 15 & 19.1258 & 18.7216 & 19.1264 & 18.7228 \\
\hline 16 & 19.7817 & 19.4681 & 19.7817 & 19.4681 \\
\hline 17 & 23.0739 & 22.4080 & 23.0736 & 22.4096 \\
\hline 18 & 23.4238 & 22.9447 & 23.4245 & 22.9457 \\
\hline 19 & 35.3863 & 34.8404 & 35.3868 & 34.8414 \\
\hline 20 & 37.8188 & 36.9723 & 37.8188 & 36.9723 \\
\hline 21 & 59.5431 & 58.1663 & 59.5429 & 58.1664 \\
\hline 22 & 65.9541 & 65.3731 & 65.9551 & 65.3744 \\
\hline 23 & 100.6465 & 97.5208 & 100.6465 & 97.5209 \\
\hline 24 & 110.2056 & 109.1565 & 110.2079 & 109.1592 \\
\hline
\end{tabular}

Similarly, the singular value decomposition (SVD) was obtained for the base and stressed cases. The SVD results are given in Table 2. The SVD results have confirmed the same results as the modal analysis method.

The Q-V curves and P-V curves for the buses 30, 29, 24, and 23 were computed and are shown in Figures 3 and 4 . These curves are used to determine the MW- and MVAR- distance to the voltage instability point of the weakest load buses. The P-V curves at different power factors for the weakest bus (bus 30) are also computed and are shown in Figure 5. From the curves it can be observed that buses 30 and 29 have less reactive power margins (i.e. less stability margins).

These agree with the bus participation factors given in Table 3. From Table 2, these buses have high participation in the critical mode which is on the verge of becoming unstable. The advantage of modal analysis is that it identifies groups of buses, which participate in the voltage instability. 


\section{AL-KHUSAIBI, ELLITHY and IRVING}

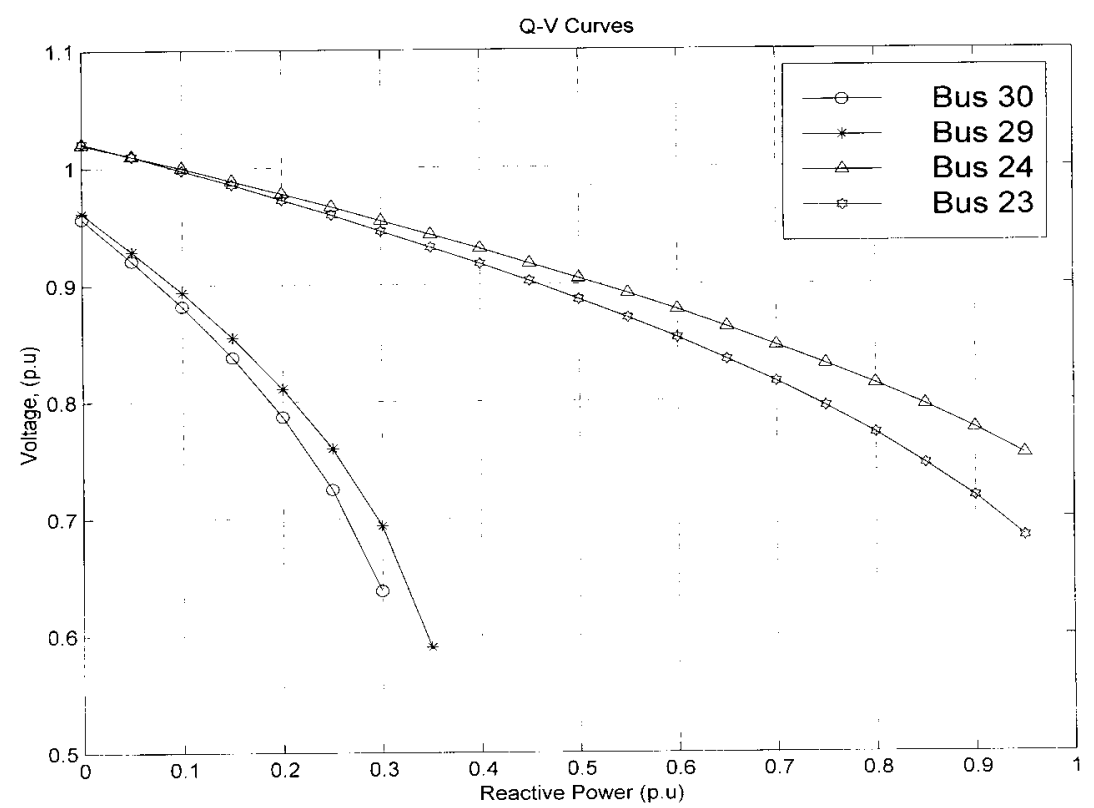

Figure 3. Q-V curves for the load buses 30, 29, 24 and 23

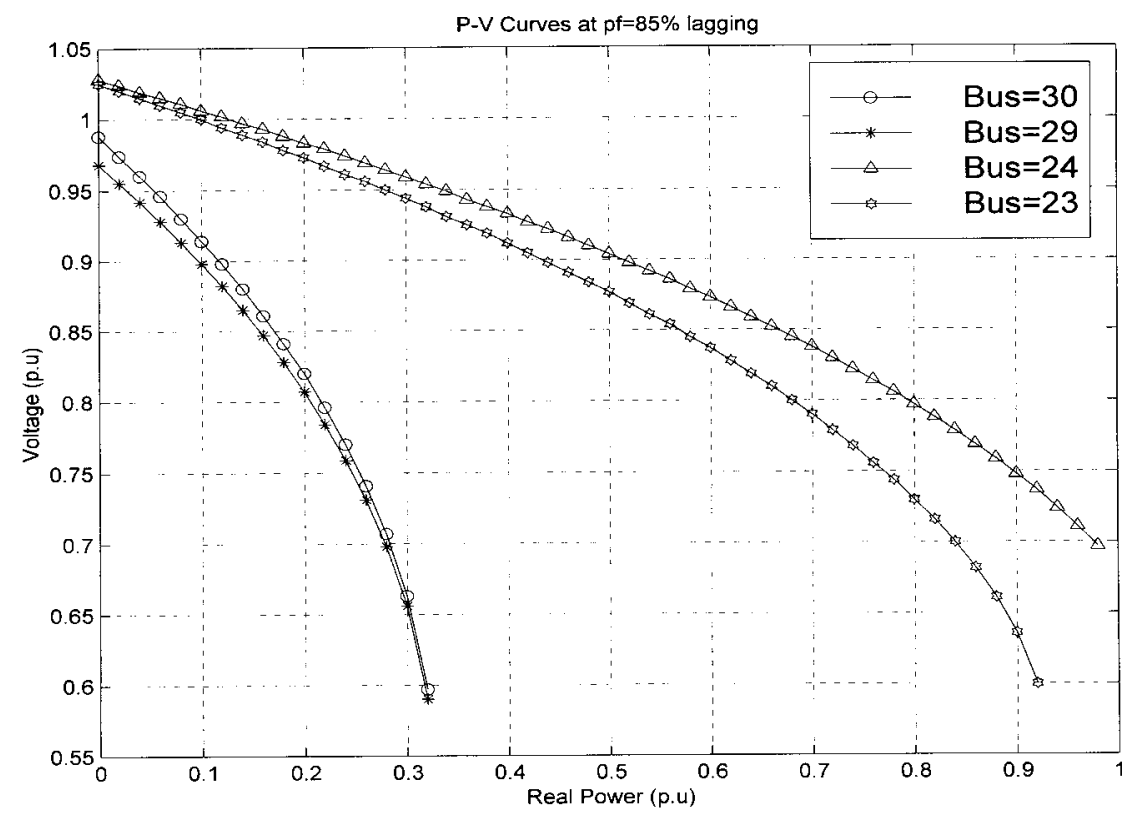

Figure 4. P-V curves for the load buses 30, 29, 24 and 23 
Table 3. Participation factors of system buses for base case and stressed case

\begin{tabular}{|c|c|c|}
\hline & $\begin{array}{l}\text { Base Case } \\
\lambda_{1}=0.506\end{array}$ & $\begin{array}{l}\text { Stressed Case } \\
\lambda_{1}=0.0371\end{array}$ \\
\hline $\begin{array}{c}\text { Bus } \\
\#\end{array}$ & $\begin{array}{l}\text { Participation } \\
\text { Factor }\end{array}$ & $\begin{array}{l}\text { Participation } \\
\text { Factor }\end{array}$ \\
\hline 3 & 0.0004 & 0.0001 \\
\hline 4 & 0.0005 & 0.0001 \\
\hline 6 & 0.0005 & 0.0002 \\
\hline 7 & 0.0002 & 0.0001 \\
\hline 9 & 0.0037 & 0.0004 \\
\hline 10 & 0.0121 & 0.0011 \\
\hline 12 & 0.0037 & 0.0003 \\
\hline 14 & 0.0081 & 0.0006 \\
\hline 15 & 0.0111 & 0.0009 \\
\hline 16 & 0.0079 & 0.0006 \\
\hline 17 & 0.0115 & 0.0009 \\
\hline 18 & 0.0165 & 0.0010 \\
\hline 19 & 0.0179 & 0.0011 \\
\hline 20 & 0.0172 & 0.0011 \\
\hline 21 & 0.0176 & 0.0018 \\
\hline 22 & 0.0189 & 0.0021 \\
\hline 23 & 0.0238 & 0.0029 \\
\hline 24 & 0.0395 & 0.0075 \\
\hline 25 & 0.1055 & 0.0413 \\
\hline 26 & 0.1729 & 0.0454 \\
\hline 27 & 0.1028 & 0.0762 \\
\hline 28 & 0.0025 & 0.0013 \\
\hline 29 & 0.1934 & 0.2389 \\
\hline 30 & $0.2 \quad 18$ & 0.574 \\
\hline
\end{tabular}

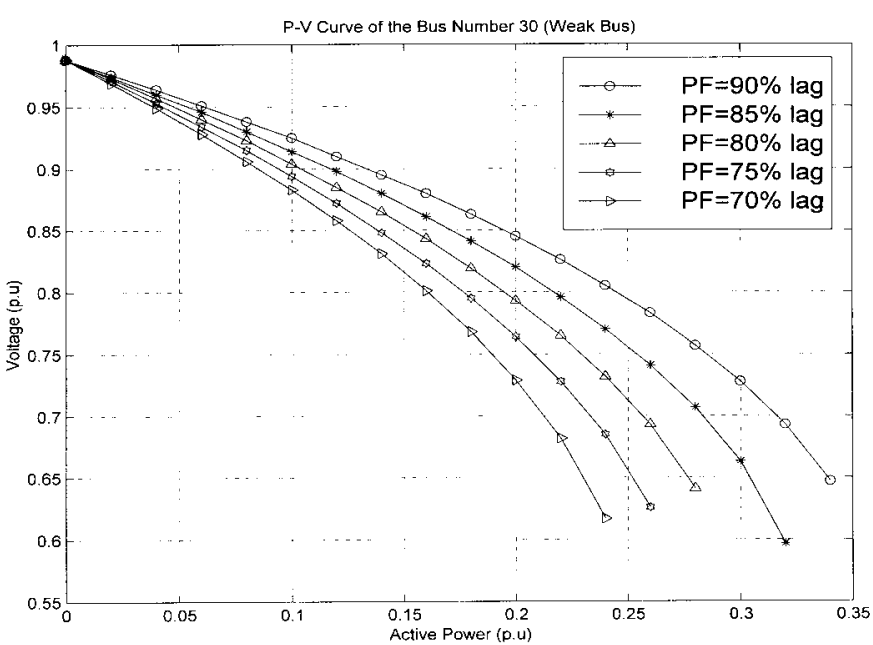

Figure 5. P-V curves for bus 30 at different power factors. 


\section{AL-KHUSAIBI, ELLITHY and IRVING}

\section{Conclusions}

The Methods for static analysis of voltage stability problems have been briefly described in this paper. Based on these methods, indices are determined to predict proximity to voltage collapse. Some of these methods were applied on the IEEE 30-bus system for demonestration of these techniques. Other methods and techniques (Carpenter et al, 1984; Tamura et al, 1982; El-Keb and Max, 1995; Kwanti et al, 1986; Chang and $\mathrm{Su}, 1998$ ) are mentioned in the references but due to space limitation these have not been discussed in this paper.

\section{References}

BARBIER C., and BARRET, J.P. 1980. Analysis of Phenomena of Voltage Collapse on Transmission System. Review Generale de Ióelectricite, 89: 672-690.

BEGOVIC, M.M. and PHADKE, A.G. 1992. Control of Voltage Stability Using Sensitivity Analysis. IEEE Trans. on Power Systems, 7: 114-123.

BULLOK G.C. 1990. Cascading Voltage Collapse in West Tennessee, August 22, 1987. 44 ${ }^{\text {th }}$ Annual Protective Relaying Conference, Georgia Institute of Tech.

CARPENTIER J., GIRARD, R. and SCANO, E., 1984. Voltage Stability Collapse Proximity Indicators Compound From An Optimal Power Flow. $8^{\text {th }}$ Power System computing Conference, Helsinki, 671-678.

CHEBBO, A.M., IRVING, M.R. and STERLING, M.J.H. 1992. Reactive Power Dispatch Incorporating Voltage Stability. IEE Proceedings-C, 139: 253-260.

CHEBBO, A.M., IRVING, M.R. and STERLING, M.J.H.1992.Voltage Collapse Proximity Indicator: Behavior and Implications. IEE Proceedings-C, 139: 241-252.

CIGRE TASK FORCE 38.02.10. 1993. Modeling of Voltage Collapse Inducing Dynamic Phenomena. CIGRE Technical Report.

COUNAN C. et al, 1993. Major incidents on the French Electric System - Potentiality and Curative Measures. IEEE Trans. on Power Systems, 8: 879-886.

CUTSEM, T. 1991. A Method to Compute Reactive Power margins with respect to Voltage. IEEE Trans. on Power Systems, PWRS-6: 145-156.

D’AQUILA, R., MILLER, N.W., JIMMA, K.M., SHEHAN, M.T. and COMERGYS, G.L., 1993. Voltage stability of the Puget Sound System under Abnormally Cold Weather Conditions. IEEE Trans. on Power Systems, 8: 11331142.

DeMACRO, C. and OVERBYE, T. 1990.An Energy based security Measure for Assessing Vulnerability to Voltage Collapse. IEEE Trans. on Power, 5: 419-427.

ELlithY, K., GASTli, A., AL-ALAWI, S., AL-HINAI, A. and AL-ABRI, Z. 2000. Voltage Stability Analysis for Muscat Power System under Summer Weather Conditions, 5: 35-45.

El-KEIB, A. and MA, X. 1995. Application of Artificial Neural Networks In Voltage Stability Assessment. IEEE Trans. on Power Systems, 10: 1890-1896.

FLATABO, N. and DOMMEL, H. 1990. Voltage Stability Condition in a Power Transmission System calculated by Sensitivity Methods. IEEE Trans. on Power Systems, 5: 1286-1293.

GANIZARES C.C., de SOUZA A.C., and QUINTANA. 1996. Comparison of Performance Indices for Detection of Proximity to voltage Collapse. IEEE Trans. On Power Systems, 11: 1441-1450.

GALIANA F.D., and ZENG Z.C. 1992. Analysis of the Load Behavior near Jacobian Singularity. IEEE Trans. on power Systems, 7: 1529-1542.

GAO, B., MORISON, G. and KUNDUR, P. 1992. Voltage Stability Evaluation Using Modal Analysis. IEEE Trans. on Power Systems, 7: 1423-1543.

IEEE WORKING GROUP ON VOLTAGE STABILITY. 1990. Voltage Stability of Power Systems: Concepts, Analytical Tools, and Industry Experience. IEEE Special Publication 90TH358-2-PWR.

JESASURYA, B. 1990. Application of Artificial Neural Networks In Voltage Stability Evaluation. Electric Power Systems Research, 29: 85-90.

KESSEL P. and GLAVITSCH. 1986. Estimating the Voltage Stability of a power System. IEEE Trans. on Power Delivery, 1: 346-353.

KUNDUR, P. 1994. Power System Stability and Control. New York : McGraw-Hill. 


\section{STATE OF THE ART METHODS FOR ELECTRIC POWER SYSTEMS}

KURITA, A. and SAKURAI, T.S., 1988. The Power System Failure on July 23, 1987 in Tokyo. Proceedings of the $27^{\text {th }}$ Conference on Decision and Control, Austin, Texas.

KWANTI, H.G., PASRIJA A.K. and BAHAR L.Y. 1986. Static Bifurcations in Electric Power Networks: Loss of Steady-State Stability and Voltage Collapse. IEEE Trans. on Circuits and systems, CAS-33: 981-991.

LIU, C., CHANG, C. and SU, M. 1998. Neuro-Fuzzy Networks for Voltage Security Monitoring based On Synchronous Pharos Measurements. IEEE Trans. on Power Systems, 13: 326-332.

LöF, P.A., ANDERSON, G. and HILL, D.J. 1993. Voltage Stability Indices for Stressed Power System. IEEE Trans. on Power Systems, 8: 326-335.

LöF, P.A., SMED, T., ANDERSON, G. and HILL, D.J. 1992. Fast Calculation of a Voltage Stability Index. IEEE Trans. on Power Systems, 7: 54-64.

MANSOUR, Y., XU, W., ALVERADO, F. and RINZIN, C. 1994. SVC Placement Using Critical Modes of Voltage Instability. IEEE Trans. on Power Systems, 9: 757-763.

MORRISON, G., GAO, G. and KUNDUR, P. 1993. Voltage Stability Analysis Using Static and Dynamic Approaches. IEEE Trans. on Power Systems, 8: 1159-1171.

MILLER, T.J.E. 1982. Reactive Power Control In Electric Systems. John Wiley \& Sons.

Nagao, T., Tanak, K. and Tekenaka, K., 1997. Development of Static and Simulation Programs for Voltage Stability Studies of Bulk Power System. IEEE Trans. On Power Systems, 12: 273-281.

OVERBYE, T. and DeMACRO, C. 1995. Improved Power System stability Assessment Using Energy Method. IEEE Trans. on Power Systems, 6: 1890-1896.

PAL, P. 1992. Voltage Stability Conditions Considering Load Characteristics. IEEE Trans. on Power Systems, 7: 243249.

SCHLUETER, R. 1998. A Voltage Stability Security Assessment Method. IEEE Trans. on Power Systems, 13: 14231438.

SEYDEL, R.1988. From Equilibrium to Chaos-Pratical Bifurcation and Stability Analysis. Elsevier Science, NorthHolland.

SUZUKI, M., WADA, S., ASANO, T. and KUDO, K. 1992. Newly Developed Voltage Security Monitoring System. IEEE Trans. on Power Systems, 7: 965-972.

TAMURA, Y., MORI, H. and IWAMOTO, S. 1982. Relationship between Voltage Stability and Multiple Load Flow Solutions in Electric Systems. IEEE Trans. on Power Apparatus and Systems, PAS-102: 1115-1123.

TAYLOR, C. W. 1994. Power System Voltage Stability. McGraw-Hill, New York.

THOMAS R.J., and TIRANUCHIT A., 1986. Voltage Instabilities in Electric Power Networks. Proceeding of Eighteenth Southeast Symposium on Systems Theory, 359-363.

VAAHEDI, E. MANSOUR, Y. and SUN, D. 1999. Large Scale Voltage Stability Constrained Optimal Planning and Voltage Stability Applications Using Existing OPF/Optimal Var Planning Tools. IEEE Trans. on Power Systems, 14: $65-74$.

VENIKOV V.A., STROEV V.A. and IDELCHICK V.I. 1975. Estimation of Electric Power System Steady State Stability in Load Flow calculation. IEEE Trans. on power Apparatus and Systems, PAS-94: 1034-1041.

YOKOYAMA, A. and SEKINE, Y. 1989. A Static Voltage Stability Index Based On Multiple Load Flow Solutions. Proc. of the Bulk Power System Voltage- Phenomena Stability and Security, Missouri.

YORINO, N., HARADA, S. and CHEN, H. 1997. A Method To Approximate a Closet Loadability Limit Using Multiple Load Flow Solutions. IEEE Trans. Power System, 12: 424 - 429.

Received 9 September 2000

Accepted 10 August 2000 